\title{
Species Identification of Mustelids by Comparing Partial Sequences on Mitochondrial DNA from Fecal Samples
}

\author{
Takahiro MURAKAMI ${ }^{1)}$ \\ ${ }^{1)}$ Laboratory of Wildlife Biology, Division of Veterinary Science, Graduate School of Veterinary Medicine, Hokkaido University, 060- \\ 0818 Sapporo, Japan
}

(Received 18 September 2001/Accepted 20 December 2001)

ABSTRACT. Nucleotide sequences of cytochrome b/tRNA/D-loop region on mitochondrial DNA of mustelids feces were compared to identify species. PCR amplification of target sequence for 47 (24.9\%) feces and species identification of five feces (2.6\%) out of 189 feces, collected at several study sites in Hokkaido, were successful. Species of three feces were Martes zibellina and those of other two feces were Martes melampus and Mustela itatsi. The low success rate of identification appeared to be due to failure of PCR amplification by inhibitors in feces. It was suggested that the method used in this study was useful for not only identify mustelids species, but also analyzing their genetic relationships.

KEY WORDS: fecal sample, Martes zibellina, mitochondria DNA, mustelid, nucleotide sequence.

Identification of feces is an important technique to reveal feeding habitat or habitat use of wildlife. However, as feces of Mustelids resemble each other, species identification of them is difficult. Two techniques for species identification of carnivore feces were reported [2, 3]. One technique used amplification of 500-1,000 bp region of cytochrome b/ tRNA/ D-loop region on mitochondrial DNA (mtDNA) and digestion of them by restriction enzymes [2]. Another technique, using shorter part of cytochrome $b$ on mtDNA, was developed for identification of fecal samples of otter, Lutra lutra, American marten, Martes americana, and polecat, Mustela putrius [3]. However, these studies did not consider elimination of contaminant such as prey DNA. In addition, those studies did not represent applicability of methods in actual field study.

I developed a technique for species identification of mustelids feces by comparing mtDNA sequences and calculated the success rate of species identification by this technique. I also examined the sequences to analyze their genetic relationships, because it is difficult to obtain carcasses or living animals of mustelids. By using this technique, contamination by prey DNA could be effectively eliminated.

\section{MATERIALS AND METHODS}

Collection of fecal samples and extraction of DNA: Feces were collected at several sites indicated on Fig. 1. Collected feces were put into new plastic bags and stored at $-20^{\circ} \mathrm{C}$ freezer until DNA extraction. DNAs were extracted from approximately $8 \mathrm{~mm}^{3}$ of fecal samples by using the DNeasy Tissue Kits (QIAGEN, Hilden, Germany). DNAs of four species of Mustelids, sable, Martes zibellina, Japanese marten, Martes melampus, American mink, Mustela vison, least weasel, Mustela nivalis and Japanese weasel, Mustela itatsi, were also extracted from approximately $8 \mathrm{~mm}^{3}$ of liver tissues.
Nucleotide sequence analysis: A part of the mitochondrial cytochrome b/tRNA/D-loop region (521-524 bp) was PCR-amplified using 20-bp primers (5'-TGAATTGGAGGACAACCAGT-3' and 5'-CCTGAAGTAGGAACCAGATG-3': [2][8]). PCR was performed with 35 cycles $\left(94^{\circ} \mathrm{C}\right.$ for $30 \mathrm{sec}, 55^{\circ} \mathrm{C}$ for $60 \mathrm{sec}, 72^{\circ} \mathrm{C}$ for $\left.90 \mathrm{sec}\right)$ and then reaction was completed at $72^{\circ} \mathrm{C}$ for $10 \mathrm{~min}$. Total of $40 \mu \mathrm{l}$ of PCR products were purified by Qiaquick purification kit (QIAGEN). Obtained eluate was used as a template for direct sequencing by GeneAmp PCR systems 9700 (Perkin Elmer Inc., Wellesley, MA, U.S.A.) and ABI Prism ${ }^{\mathrm{TM}} 377$ (Perkin Elmer Inc.).

Data analysis: Sequences were aligned by the multiple alignment program, Clustal W ver.1.7 [9]. I calculated Kimura's two parameter [4] as a genetic distance by using a computer program, Philip ver.3.573 (Phylogeny Inference Package by Joseph Felsenstein). The haplotype which has the closest genetic distance with each fecal sample was considered to reflect the species of sample. Phylogenetic trees were reconstructed by neighbor-joining method [7] by using Philip ver. 3.573. As the major preys of mustelids are voles, Clethrionomys rutilus and Clethrionomys rufocanus [1], the contaminations by their DNAs are probable. Thus, the end part of cytochrome b region (first $112 \mathrm{bp}$ ) of the sequences of mustelids and fecal samples in this study was compared with those of the C. rutilus (Accession number; AF119274) and C. rufocanus (AF367078) derived from database "Gene bank".

\section{RESULTS}

PCR-amplification was successful for 47 (24.9\%) of fecal samples (Table 1). All of them were amplifications of target bands. However, only from five $(2.6 \%)$ fecal samples, I could read DNA sequences of target region on mtDNA (Table 1). Failures of sequencing were mainly caused by 


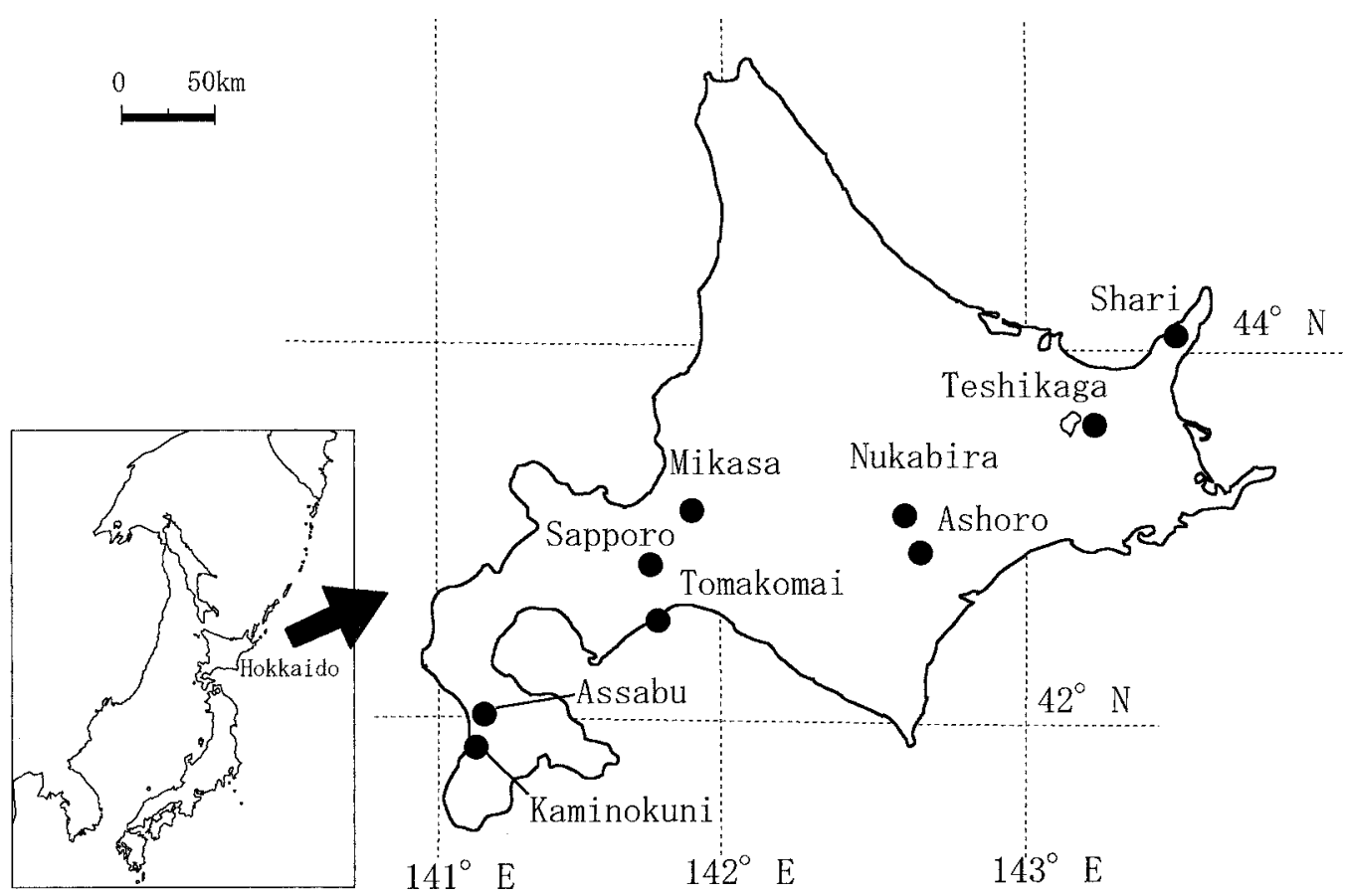

Fig. 1. Study sites (indicated by closed circle) where we collected mustelids feces.

Table 1. Numbers of total fecal samples and numbers of successfully PCR-amplified and sequenced. Numbers in parentheses indicate the percentage

\begin{tabular}{ccc}
\hline No. Samples & $\begin{array}{c}\text { PCR } \\
\text { amplification }\end{array}$ & Sequence \\
\hline 189 & 47 & 5 \\
$(100)$ & $(24.9)$ & $(2.6)$ \\
\hline
\end{tabular}

weak signals during auto sequencing.

Figure 2 shows the phylogenetic tree of five species of mustelids and five fecal samples. Species of five fecal samples were able to be identified because each of them was clustered with each mustelids species within the phylogenetic tree. D-1 was identified as an excrement of Martes melampus. D-2 was similarly identified as that of Mustela itatsi, whreas D-3, D-4, and D-5 as those of Martes zibellina.

Only one nucleotide substitution was detected between haplotype MM-1 and D-1. One nucleotide substitution was found between MZ-1 and D-3, two substitutions between MI-1 and D-2, and three substitutions between MZ-2 and D4. No difference was detected between MZ-2 and D-5.

Probability of contamination by prey DNAs were easily eliminated, because more than $25 \%$ nucleotide substitutions were found among 112 bp cytochrome $\mathrm{b}$ region between mustelids and voles DNA.

\section{DISCUSSION}

Species of five fecal samples were able to be identified. In order to monitor distribution of mustelids[5], species identification by their feces are helpful, because it is more difficult to obtain mustelids carcasses or tissues in the field. In addition, the present study is suggested to contribute to studies of genetic relationship of mustelids.

Large numbers of failures were occurred by the end of sequencing process. Firstly, PCR amplification of many samples were failed. Small numbers of DNA copies on feces and PCR inhibitors in feces were considered to be possible factors of failures. Previous studies have presented techniques to increase success rate of PCR amplification from fecal DNA samples [2,6]. These method may bring more PCR products. In addition, as DNAs in feces are seemed to be degraded, shorter region than the current study is appropriate for PCR amplification from fecal DNA [3], if there is no need to distinguish closely related species such as M. zibellina and M. melampus.

Secondary, sequencing of PCR products were often failed mainly by weak signal. Small numbers of DNA copies after PCR amplification are caused into signal weakness. Using more PCR products may bring more success of sequencing processes. Cloning of target sequence may improve the success rate of auto sequencing.

Development of studies on food habit, population structure, and habitat use of mustelids depend on improving techniques of species identification of their feces. The present 


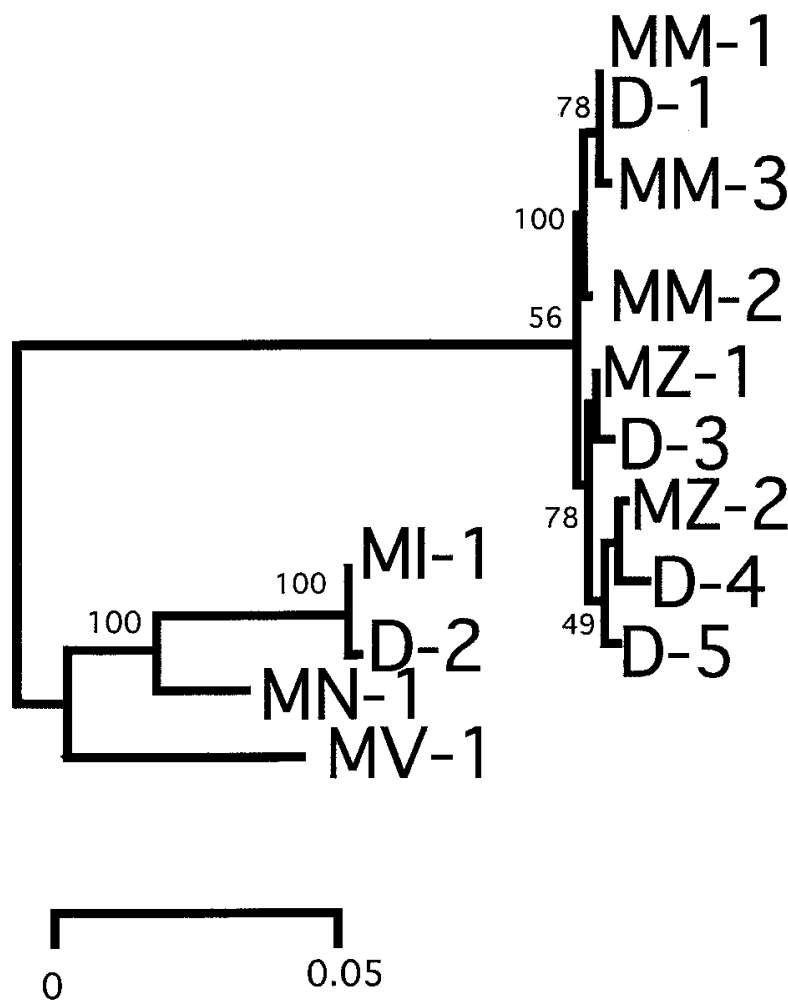

Fig. 2. The phylogenetic tree indicates the relationships between fecal samples and haplotypes of five mustelid species. Species of each haplotypes are MM: Martes melampus, MZ: Martes zibellina, MI: Mustela itatsi, MN: Mustela nivalis, and MV: Mustela vison. These haplotypes are derived from liver tissue. From D-1 to D-5 are haplotypes of fecal samples.

study is first report of sequencing fecal DNA of mustelids.

ACKNOWLEDGMENTS. I wish to thank N. Ohtaishi for his helpful suggestions. I also wish to thank; H. Okada, M. Yamanaka, Y. Masuda, M. Aida, A. Umejima, K. Hashiba,
H. Ishii, T. Fujimoto, N. Suzuki, M. Yamamoto, J. Moll, K. Moll, K. Waseda, T. Takenaka, Y. Hayashi, H. Igota, M. Asakawa, M. Kawabe and S. Sasano. Thanks are due to; Japan Highway, Kushiro and Abashiri Development and Construction Departments, Teshio and Nakagawa experimental forests of Hokkaido University, Shiretoko Museum and Shiretoko Nature Center. This study was partly supported by a grant from the "Hokscitec", Hokkaido Foundation for the Promotion of Scientific and Industrial Technology.

\section{REFERENCES}

1. Buskirk, S.W., Ma, Y., Xu, L. and Zhaowen, J. 1996. Diets of, and prey selection by, sables (Martes zibellina) in northern China. J. Mammal. 77: 725-730.

2. Foran, D. R., Crooks, K.R. and Minta, S. C. 1997. Species identification from scat: an unambiguous genetic method. Wildl. Soc. Bull. 25: 835-839.

3. Hansen, M. M. and Jacobsen, L. 1999. Identification of mustelid species: otter (Lutra lutra), American marten (Martes americana), and polecat (Mustela putrius), by analysis of DNA from fecal samples. J. Zool. Lond. 247: 177-181.

4. Kimura, M. 1980. A simple method for estimating evolutionary rate of base substitutions through comparative studies of nucleotide sequences. J. Mol. Evol. 16: 111-120.

5. Murakami, T. and Ohtaishi, N. 2000. Current distribution of the sable and introduced Japanese marten in Hokkaido. Mammal Study 25: 149-152.

6. Murphy, M.A., Waits, L.P. and Kendall, K.C. 2000. Quantitative evaluation of fecal drying methods for brown bear DNA analysis. Wildl. Soc. Bull. 28: 951-957.

7. Saitou, N. and Nei, M. 1987. The neighbor-joining method: new method for reconstructing phylogenetic trees. Mol. Biol. and Evol. 4: 406-425.

8. Shield, G. and Kocher, T. 1991. Phylogenetic relationships of North American ursids based on analysis of mitochondrial DNA. Evolution 45: 218-221.

9. Thompson, J. D. Higgins, D. G. and Gibson. T.J. 1994. Clustal $\mathrm{W}$ : improving the sensitivity of progressive multiple sequence alignment through sequence weighting, positions-specific gap penalties and weight matrix choice. Nucleic Acids Res. 22: 4673-4680. 